\title{
A REVIEW OF BLDC MOTOR FOR ELEVATOR APPLICATION
}

\author{
VINAYAK C. MAHAJAN ${ }^{1} \&$ NITIN R. BHASME ${ }^{2}$ \\ ${ }^{I}$ Research Scholar, Department of Electrical Engineering, Government College of Engineering, Aurangabad, India \\ ${ }^{2}$ Faculty, Department of Electrical Engineering, Government College of Engineering, Aurangabad, India
}

An elevator is a system basically used for vertical transportation of goods or humans. In past and present many motors has been used or in use for Elevator application. Out of which each type of motor has its own merits as well as demerits. By the use of power electronic converters and controllers, DC motors have been replaced by Induction motor and permanent magnet synchronous motor for elevator application. Today, many motor manufacturing industries are focusing on Brushless Direct Current (BLDC) motor due to its smooth speed control, high power density and fewer complexities in power converter and controllers when operated with DC supply \& compared with other motors. This paper gives the review of BLDC motor for Elevator application and also the presentation of some prerequirements \& calculations of finding the torque, angular speed and rotational speed for BLDC motor design approach. Further different software such as ANSYS-MAXWELL or MATLAB SIMULINK can be used for the analysis for BLDC motor.
\end{abstract}

KEYWORDS: Brushless Direct Current (BLDC) Motor, Elevator, Induction Motor (IM) \& Permanent Magnet Synchronous Motor (PMSM)

Received: Jun 15, 2018; Accepted: Jul 06, 2018; Published: Aug 02, 2018; Paper Id: IJEEERAUG20182

\section{INTRODUCTION}

An elevator is a system basically used to transport people or goods. Earlier many industries have been manufacturing three phase Induction Motors for elevator application and most of all elevator systems are coupled with 3 phase IM to carry out lifting action. However, today, research is based for efficient, reliable and better speed operation conventional motors to be replaced by 3 phase IM [1].

In old days DC series motors were the only optimal for elevator due to its easy control and good ride quality. After the advancement in power electronics, Induction motor took control over the elevator. This gives its unique assets like lower cost, stronger system and requires very less maintenance than DC motors. When elevators operate with the Induction motor the required speed can be achieved with the help of Mechanical Gear Box and need frequent lubrication to obtain smooth operation. It is not necessary in case of Permanent Magnet Synchronous Motor (PMSM) when operated with the inverter circuit with a gearless design. Actually, by using the power electronics circuits such as inverters with IM it could be possible to manage the required speed but design of IM with increasing no of poles becomes costly. It is limited to six poles whereas it can be possible to obtain 50 numbers of poles in case of PMSM.

Although raising poles and dropping frequency at the same time results raising torque but drop in speed. Generally, there are some limitations related to conventional systems like poor efficiency, unnecessary huge design, noise problem, less reliable, vibrant system, maintenance, and repair problem. Also, need of separate 
installation room for the machine at the top of the building [2]-[3]. Thus to overcome these problems this paper gives the basic approach to design BLDC Motor for elevator application.

\section{ELECTRIC MOTORS FOR ELEVATOR}

Previously various motors are used for elevator application such as,

\section{Motor}

There are two important characteristics related to the DC motor. First, by varying the voltage speed can be controlled but while elevator cabin about to reach required position abrupt stopping occurs which results in less comfort for passengers and machinery becomes obstinate.

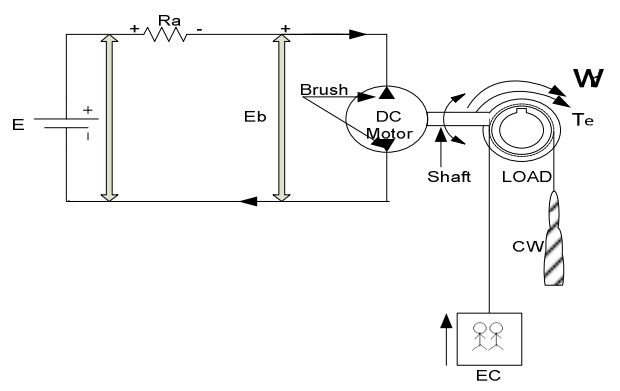

Figure 1: DC Motor for Elevator Application

Second, it can be possible to reverse a direction of the DC motor by changing the polarity of electric supply. Thus better speed control \& easy reversibility are the only merits related with DC motor. But need of frequent maintenance, replacement of electromechanical brush commutator for continuous operation, hazardous fire due to brush dust, increase in running cost, sparking problem at brush commutator assembly and radio frequency interference with electronic circuit operated with DC motor are major key issues related with DC motor when operated for elevator application [4].

\section{AC Motors}

There are two types of AC motors i.e. synchronous motor \& asynchronous motor that is nothing but Induction Motor. Generally, 5 H.P. motors are designed for elevator application where stator winding of the motor is energized with three-phase AC power supply which produces a rotating magnetic field due to the cyclic behavior of AC power. These three phase stator windings are connected with star or delta fashion $\&$ thus the production of three rotating magnetic fields occurs within motor. Recently PMSM has occupied the market because of its high efficiency; it has high power density \& easy to control. Thus today, elevator manufacturing companies prefer PMSM for elevator application.

Mechanical speed reducer can be obtained by using the PMSM \& inverter circuit together and speed can be controlled with the help of better motor design. Torque and speed can be controlled with the variation in the number of poles \& frequency. Also for the same load capacity in the dimensions and weight point of view when we compare PMSM without gearbox and Induction Motor with gearbox the 50\% compactness occurs in case of PMSM. Therefore it became a trend to adopt gearless PMSM for lower speed and higher torque elevator applications. But due to the presence of harmonics vibration occurs which disturbs lifting operation. Now research is focused on to reduce harmonics and vibrations in case of PMSM [4]. 
By the use of a switched reluctance motor for elevator, efficiency can be 75 to $80 \%$. This improvement in efficiency obtained by reducing various losses like eddy, hysteresis, switching losses which generally occur in the converter circuit the efficiency can also be improved by adopting different optimization techniques. Also Further the research work is going on in the flux analysis where it can be possible to reduce the losses in motor and torque profile improvement by optimizing the required stator and rotor angle [5].

In case of IM when load increases torque also increases thus speed of the motor decreases. It was difficult to maintain required speed for elevator action while coupled with IM before the invention of VFDs. VFD i.e. variable frequency drive is nothing but a power electronic circuit which is used to control the speed of IM by varying voltage and frequency. Due to VFDs, the sudden change occurred in elevator manufacturing industries and IM took control of the elevator and also replaced DC motor.

To understand precise speed controlling \& detailed operation of elevator system operated with IM and VFD, further existing installed elevator system with 5 person's capacity has studied. The overall elevator system is installed for $16.2 \mathrm{~m}$ height building. Total weight of a fully loaded elevator cabin is $310 \mathrm{~kg}$ where each person weight is assumed as $68 \mathrm{~kg}$. $500 \mathrm{~kg}$ counterweight is attached to this elevator. This weight is 1.5 times to the weight of the fully loaded elevator cabin. A weight of this counterweight has decided as per the elevator standard. IG5A variable frequency drive is used to control this elevator system. Figure 2 shows the VFD circuit diagram in which AC to DC converter and DC to AC inverter are coupled together with DC link capacitors and inductors.

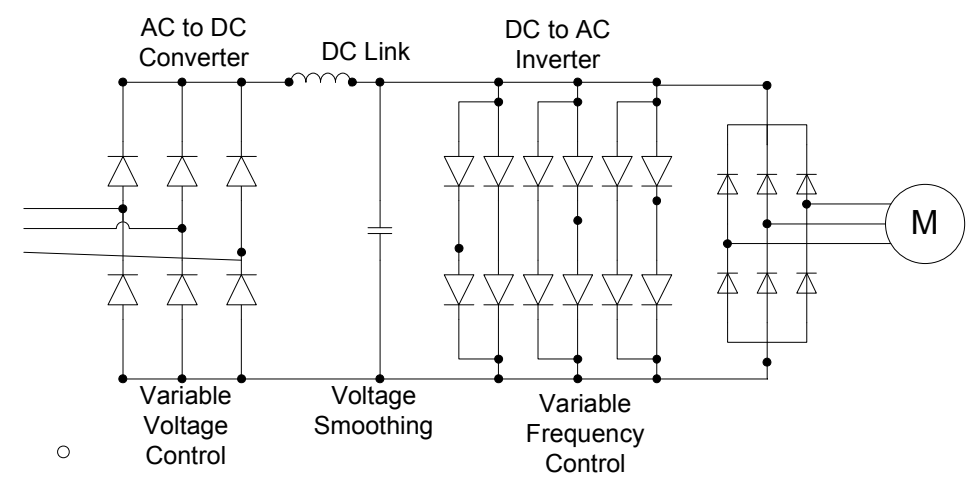

Figure 2: VFD Circuit for Induction Motor

AC to DC converter fed by 415/460 volts three-phase AC power supply. If any variation in the supply observed or sensed by the VFD then the motor gets disconnected from the supply. Also speed regulation of elevator cabin during landing and running mode can be achieved with small control wire which is coming from the speed control potentiometer known as speed governor. This potentiometer basically carries DC signals ranged up to 10V DC. This speed governor consists diverter pulley at the top and bottom of the building. It prevents over speeding of the elevator with the help of electrical switches. These electrical switches are used to lock the over a speed of elevator cabin. Reverse direction of the motor can be obtained with the help of control loop at the elevator control panel. Vertical speed for elevator cabin is 0.65 $\mathrm{m} / \mathrm{s}$ decided as per elevator standard. Rise for elevator cabin is $10.05 \mathrm{~m}$ including three stops on three floors. Elevator cabin and counterweight are connected together with the help of three ropes mounted on the main sheave. For this elevator star connected 5 H.P. $(3.8 \mathrm{~kW}) 3$ phase induction motor with gearbox has used for lifting operation. The rated speed is 960 rpm. The supply voltage for the motor is $400 / 440$ volts AC \& operated on $50 \mathrm{~Hz}$ frequency. Rated current is $8.5 \mathrm{~A}$. and Eclass insulation has provided to the windings. 
The output of DC to AC inverter gives to the motor and the speed can be achieved by the varying frequency irrelevant of supply frequency i.e. $50 \mathrm{~Hz}$ as per the speed requirement. There are two provisions given one for manual operation and other is for VFD control. A manual operation carried out by using open start button and closed stop button which is at the outside of the cabin and VFD control operation can be achieved by feedback signal which is obtained from tachometer connected to the motor shaft. This VFD checks the system status every time before opening the cabin. If any fault sensed by the VFD it disconnects the motor from the main supply. Only need to take care of DC link capacitors which basically hold the charges even though the power supply has been disconnected. Thus it is necessary to give some provisions to avoid shortening of these capacitors.

Reverse direction of the motor can be obtained with the help of control loop at the elevator control panel. The IM and VFD control panel is installed at the top of the building where $14.5 \mathrm{ft}$ (4.42 $\mathrm{m}$ ) space has to maintain between the top floor and machine room as per elevator standard to reduce vibrations. And also $5 \mathrm{ft}$ (1.55 m) pit height is left to construct the buffers at the bottom of the building. These buffers are used for settle down the counterweight. The machine room also contains the user interface with alphanumeric display including various indicating LEDs to indicate system status in running mode, halt mode, fault mode and reverse direction mode at the front panel of the VFD.

\section{BLDC Motor}

With various advantages like higher torque to current ratio, higher efficiency \& high power density BLDC motor has secured the special space in modern drive industry. Because of these advantages, BLDC motor can replace the conventional motors [6]-[7]. Et al Jeon observed many advantages of BLDC motor \& further analysis and design carried out using a new simulation model [6]. Also, some research work is carried out to achieve high efficiency \& better speed control of BLDC motor [8]-[12]. Regenerative braking can be possible in case of BLDC motor when the BLDC motor studied for electric vehicle applications [13]-[16]. According to these studies, it can be possible to use BLDC motor for elevator application.

\section{ELEVATOR OPERATION}

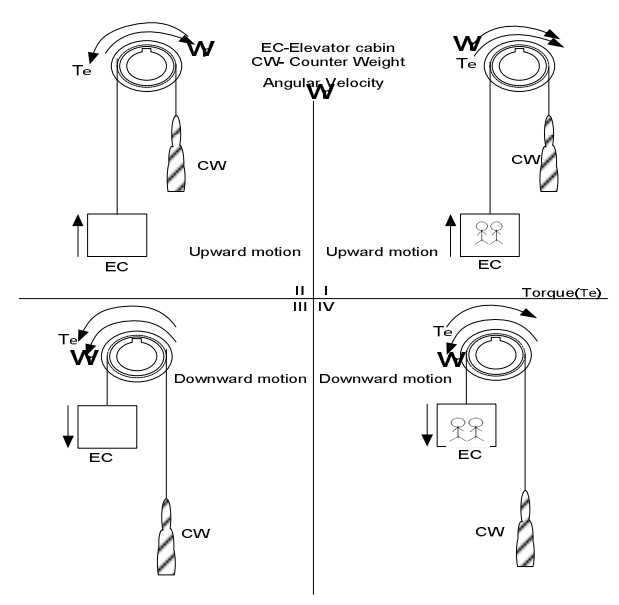

Figure 3: Four Quadrant Operation of the Elevator System

Four quadrants working operation of the elevator is proposed in this paper when coupled with the BLDC motor. This operation is basically depends upon the elevator cabin weight as well as counterweight relation \& direction of elevator cabin movement. 
Figure 3 shows the four quadrant operation of the elevator system in which quadrant I \&III gives the forward motoring and reverse motoring operation with fully loaded and empty elevator cabin respectively. Whereas quadrant II \& IV gives the forward and reverses braking operation with an empty and loaded cabin respectively. To carry out lifting and braking operation it is mandatory to keep the weight of counterweight 1.5 times to the loaded cabin. This working can be carried out with the net weight difference between the counterweight and elevator cabin. Mechanical gearbox can be used to obtain the required speed for particular torque by adjusting the gear ratio. Further, the torque and speed calculations and equations are derived to design the BLDC motor for elevator application.

\section{PRE-REQUIREMENTS FOR ELEVATOR SYSTEM}

Torque and speed are the primary components which required for designing of the BLDC motor. With the help of cabin vertical moving speed, weight capacity of the cabin, type of suspension \& diameter of the pulley the required formula can be derived as,

\section{The Formula}

The basic method can be used in most of the cases to select the size of the motor. The worst case is taken as that of lifting a fully loaded elevator cabin in the up direction at rated speed (assuming that the counterweight ratio is $50 \%$ or less). These calculations can be achieved by the following stages:

The fully loaded passenger mass is reduced by the amount of counterweight. This represents the out of balance mass. This is multiplied by the acceleration of gravity, to determine the force in Newton needed to move this out of balance mass against gravity in the up direction. Multiplying this force by the rated speed gives the rate of flow of energy, or in other words the power in watts. This represents the net output power of the system. This calculated net output power has to flow through the system, and thus a larger value of power has to be supplied to account for all losses in the shaft and gearbox. Thus, the net output power is divided by the shaft efficiency and the gearbox efficiency to provide the required motor output power rating. The efficiency of the shaft and the gearbox (forward) assumed 75\%. The forward efficiency of the gearbox is taken in this case because the motor is driving. The reverse efficiency is only taken if the braking calculation is being carried out. The forward and reverse efficiencies for worm gearbox are different.

Therefore,

$$
\mathrm{P}_{\mathrm{m}}=\frac{\mathrm{n} \times \mathrm{M}_{\text {Carry }} \times \mathrm{g} \times \mathrm{V}_{\mathrm{EC}} \times(1-\mathrm{cf})}{\eta}
$$

Where,

$\mathrm{n}=$ is the rated passenger number in the car;

$M_{\text {Carry }}=$ weight of each passenger $=68 \mathrm{~kg} /$ passenger;

$\mathrm{g}=$ the acceleration due to gravity $=9.81 \mathrm{~m} / \mathrm{s}^{2}$;

$\mathrm{V}_{\mathrm{EC}}=$ is the rated speed of elevator cabin;

$\mathrm{cf}=$ is the counterweight factor (a factor less than 1$)$;

$\eta=$ is the total efficiency of the installation 
(taken around $75 \%$ ).

The counterweight ratio is important, it accounts for the fact that if the counterweight ratio is less than $50 \%$, then the worst case scenario would be for a full elevator cabin moving upward. For example, if the counterweight ratio is only $40 \%$, then when the elevator cabin is fully loaded, only $40 \%$ weight of the passengers is compensated by the weight of the counterweight, and the motor has to provide enough torque to lift the other $60 \%$. Using a counterweight ratio of $40 \%$ is quite common. To design a motor for the capacity of 5 person elevator system, let the weight of elevator cabin will be $375 \mathrm{~kg}$ (for 5 passengers each of $68 \mathrm{~kg}$ weight i.e. $(5 \times 68 \mathrm{~kg}=340 \mathrm{~kg}), 1.0 \mathrm{~m} / \mathrm{s}$ elevator cabin (EC) velocity, and $3: 1$ suspension ratio then,

\section{Case1}

- Torque of the motor can be calculated as,

$\mathrm{T}_{\mathrm{m}}=\frac{\mathrm{R}_{\text {pulley }} \times \mathrm{g} \times \mathrm{M}_{\text {Carry }} \times \eta}{\mu}$

Where,

$\mathrm{T}_{\mathrm{m}}=$ motor torque $\mathrm{Nm}$

$\mathrm{R}_{\text {pulley }}=$ radius of the pulley

$\mathrm{g}=$ gravitational force $=9.81 \mathrm{~m} / \mathrm{s}^{2}$

$\mathrm{M}_{\text {Carry }}=$ maximum weight caring capacity

$\mu=$ coefficient of suspension type $=2$

[1=for direct suspension; 2=for 2:1 suspension $\& 3=$ for $3: 1$ suspension]

$\eta=$ well and rope system efficiency $=75 \%$

Thus,

$\mathrm{T}_{\mathrm{m}}=\frac{\mathrm{R}_{\text {pulley }} \times \mathrm{g} \times \mathrm{M}_{\text {Carry }} \times \eta}{\mu}$

$\mathrm{T}_{\mathrm{m}}=\frac{0.12 \times 9.81 \times(5 \times 68) \times 0.75}{3}$

$\mathrm{T}_{\mathrm{m}}=100.62 \mathrm{Nm}$

- Motor rated angular speed and rotational speed can be calculated as,

$$
\begin{aligned}
& \omega=\mu \times\left[\frac{\mathrm{V}_{\mathrm{EC}}}{\mathrm{R}_{\text {pulley }}}\right] \mathrm{rad} / \mathrm{sec} \\
& \omega=3 \times\left[\frac{1.0}{0.12}\right] \mathrm{rad} / \mathrm{sec} \\
& \omega=25 \mathrm{rad} / \mathrm{sec} \\
& \mathrm{N}=\omega \times\left[\frac{60}{2 \pi}\right] \mathrm{rpm}
\end{aligned}
$$




$$
\begin{aligned}
& \mathrm{N}=25 \times \frac{60}{2 \pi} \mathrm{rpm} \\
& \mathrm{N}=238.73 \mathrm{rpm}
\end{aligned}
$$

From equation $4,5 \& 6$ we have calculated values of torque $\left(\mathrm{T}_{\mathrm{m}}\right) \mathrm{Nm}$ and angular speed $(\omega) \mathrm{rad} / \mathrm{sec} \& \mathrm{rotational}$ speed in(N) rpm. From this, we can find out the rated output power of the motor by using the following formula,

$$
\begin{aligned}
& \mathrm{P}_{\mathrm{m}}=\mathrm{T}_{\mathrm{m}}(\mathrm{Nm}) \times \omega(\mathrm{rad} / \mathrm{sec}) \mathrm{Watt} \\
& \mathrm{P}_{\mathrm{m}}=100.62 \times 25 \\
& \mathrm{P}_{\mathrm{m}}=2515.5 \text { Watts }=2.515 \mathrm{~kW}
\end{aligned}
$$

\section{Case2}

From equation (1) we have considered the counterweight is only $40 \%$ i.e. when elevator cabin is fully loaded only $40 \%$ of the weight of the elevator cabin is compensated by the weight of counterweight, \& motor has to provide enough torque to lift the other $60 \%$.

Thus from equation (1) the rated power obtained as,

$$
\begin{aligned}
& \mathrm{P}_{\mathrm{m}}=\frac{\mathrm{n} \times \mathrm{M}_{\text {Carry }} \times \mathrm{g} \times \mathrm{V}_{\mathrm{EC}} \times(1-\mathrm{cf})}{\eta} \\
& \mathrm{P}_{\mathrm{m}}=\frac{5 \times 68 \times 9.81 \times 1.0 \times(1-0.4)}{0.75} \\
& \mathrm{P}_{\mathrm{m}}=2668.32 \text { Watts }=2.668 \mathrm{~kW}
\end{aligned}
$$

Thus, in case 1 the counter weight factor can be calculated by substituting the $P_{m}$ obtained from equation (7) in equation (1)

$$
\begin{aligned}
& \mathrm{P}_{\mathrm{m}}=\frac{\mathrm{n} \times \mathrm{M}_{\mathrm{Carry}} \times \mathrm{g} \times \mathrm{V}_{\mathrm{EC}} \times(1-\mathrm{cf})}{\eta} \\
& 2515.5=\frac{5 \times 68 \times 9.81 \times 1.0 \times(1-\mathrm{cf})}{0.75} \\
& 0.56=(1-\mathrm{cf}) \\
& \mathrm{cf}=1-0.56 \\
& \mathrm{cf}=0.4343
\end{aligned}
$$

From equation (9) and case 2 value of 'cf' is obtained as $0.437 \& 0.4$ thus our assumptions are almost correct to design BLDC motor.

\section{SELECTION OF BLDC MOTOR}

Figure 4 shows the circuit diagram for star connected BLDC motor drive. Generally, MOSFET/IGBT switches are used for switching operation. In case of BLDC motor two phases are excited at the same time and back EMF is calculated across remaining phase. 


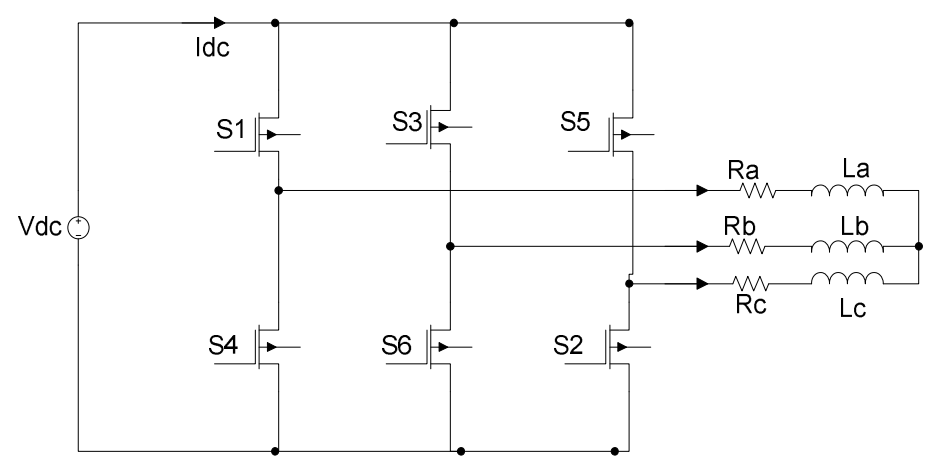

Figure 4: BLDC Motor Circuit Diagram

Thus for BLDC motor mathematical equations can be written as,

$$
\begin{aligned}
& \mathrm{V}_{\mathrm{a}}=\mathrm{i}_{\mathrm{a}} R+L \frac{d \mathrm{i}_{\mathrm{a}}}{d t}+\mathrm{E}_{\mathrm{a}} \\
& \mathrm{V}_{\mathrm{b}}=\mathrm{i}_{\mathrm{b}} R+L \frac{d \mathrm{i}_{\mathrm{b}}}{d t}+\mathrm{E}_{b} \\
& \mathrm{~V}_{\mathrm{c}}=\mathrm{i}_{\mathrm{c}} R+L \frac{d \mathrm{i}_{\mathrm{c}}}{d t}+\mathrm{E}_{c}
\end{aligned}
$$

Initially winding inductance is not considered. Winding resistance is considered for copper wire is $0.24 \Omega / \mathrm{ph}$. Thus above equations can be written as,

$$
\begin{aligned}
& \mathrm{V}_{\mathrm{a}}=\mathrm{i}_{\mathrm{a}} R+\mathrm{E}_{\mathrm{a}} \\
& \mathrm{V}_{\mathrm{b}}=\mathrm{i}_{\mathrm{b}} R+\mathrm{E}_{b} \\
& \mathrm{~V}_{\mathrm{c}}=\mathrm{i}_{\mathrm{c}} R+\mathrm{E}_{c}
\end{aligned}
$$

Where,

$\mathrm{V}_{\mathrm{a}}, \mathrm{V}_{\mathrm{b}}, \mathrm{V}_{\mathrm{c}}=$ phase voltages across $\mathrm{a}, \mathrm{b}, \mathrm{c}$ phase respectively

$\mathrm{i}_{\mathrm{a}}, \mathrm{i}_{\mathrm{b}}, \mathrm{i}_{\mathrm{c}}=$ stator phase current through a, b, c phase respectively

$\mathrm{E}_{\mathrm{a}}, \mathrm{E}_{b}, \mathrm{E}_{c}=$ Back EMF of phase $\mathrm{a}, \mathrm{b}, \mathrm{c}$ respectively

Thus in generalized format voltage equation can be written as,

$\mathrm{V}=\mathrm{I} R+\mathrm{E}_{\text {back }}$

Now, in case of BLDC motor two phases are acting at a same time and back EMF calculated across remaining phase. Thus power contributed due to two phases can be calculated as,

$$
\mathrm{P}=\frac{2}{3} \mathrm{P}_{\text {out }}
$$

Where $\mathrm{P}_{\text {out }}=$ output power watts total calculated in eq.7

Thus,

$$
\mathrm{P}=\frac{2}{3} \times 2515.5
$$


$\mathrm{P}=1677$ Watts

Current can be calculated as,

$\mathrm{I}=\frac{\mathrm{P}}{\mathrm{V}_{\mathrm{dc}}}$

$\mathrm{I}=\frac{1677}{120}=13.89 \mathrm{Amp}$

Further the back EMF can be calculated from eq. 16 as,

$\mathrm{V}=\mathrm{I} R+\mathrm{E}_{\text {back }}$

$120=(13.89 \times(2 \times 0.24))+\mathrm{E}_{\text {back }}$

$\mathrm{E}_{\text {back }}=113.33 \mathrm{~V}$

To calculate torque it is necessary to calculate torque constant $k_{t}$ and back EMF constant $k_{e}$.

Back EMF constant $k_{e}$ can be calculated as,

$\mathrm{E}_{\text {back }}=k_{e} \omega_{m}$

$k_{e}=\frac{113.33}{25}=4.53 \frac{\text { volt }}{\mathrm{rad} / \mathrm{sec}}$

According to BLDC motor theory while designing the motor for two slots per phase value of $k_{e}$ can be calculated as,

$\mathrm{E}_{\text {back }}=2 N \mathrm{~B}_{g} \mathrm{~L}_{s t} \mathrm{R}_{r 0} \omega_{m}$

Where,

$2 N=$ no. of conductors for two slots per phase

$\mathrm{B}_{g}=$ air gap flux density

$\mathrm{L}_{s t}=$ axial length of motor

$\mathrm{R}_{r 0}=$ air gap radios of magnet surface

$\omega_{m}=$ Rotor angular speed $\mathrm{rad} / \mathrm{sec}$

Thus,

$k_{e}=2 N \mathrm{~B}_{g} \mathrm{~L}_{s t} \mathrm{R}_{r 0}$

Proper selection of air gap radius of the magnet surface and an axial length of the motor value of $k_{e}$ can be calculated.

Also, torque equation will be,

$$
\begin{aligned}
& \mathrm{T}_{e}=\frac{\mathrm{E}_{\text {back }}}{\omega_{\mathrm{m}}} \mathrm{I} \\
& \mathrm{T}_{e}=2 N \mathrm{~B}_{g} \mathrm{~L}_{s t} \mathrm{R}_{r 0} \mathrm{I}
\end{aligned}
$$


$\mathrm{T}_{e}=k_{t} \mathrm{I}$

From equation $22 \& 23$ the values of $k_{e} \& k_{t}$ are same for BLDC motor,

Therefore, torque can be calculated as,

$\mathrm{T}_{e}=k_{t} \mathrm{I}$

Where I is the total current

$\mathrm{T}_{e}=4.53 \times 22.23$

$\mathrm{T}_{e}=100.70 \mathrm{Nm}$

From equation 3 and equation 26, values calculated for torque are same. Thus it can be possible to design BLDC motor of output power $2.5 \mathrm{~kW}$ for 5 persons each of $68 \mathrm{Kg}$ weight capacity of an elevator system.

Thus table 1 gives the requirements for above specified elevator load,

Table 1: Motor Specifications for Elevator

\begin{tabular}{|c|l|c|}
\hline Sr. no. & \multicolumn{1}{|c|}{ Quantity } & Ratings \\
\hline 1 & Motor torque $\left(\mathrm{T}_{\mathrm{m}}\right)$ & $100 \mathrm{Nm}$ \\
\hline 2 & Angular Speed $(\omega)$ & $25 \mathrm{rad} / \mathrm{sec}$ \\
\hline 3 & Rotational Speed $(\omega)$ & $240 \mathrm{rpm}$ \\
\hline 4 & $\mathrm{P}_{\text {out }}$ & $2.5 \mathrm{KW}$ \\
\hline
\end{tabular}

\section{CONCLUSIONS}

This paper has proposed the study of various motors previously as well as presently used for elevator application. Out of which the three-phase induction motor with VFD is most common and has its own advantages and disadvantages, also now days permanent magnet synchronous motor is also in use for elevator application but there are some problems like harmonics and torque ripple due to fluctuation in non-sinusoidal back EMF waveforms these problems can be minimized in BLDC motor as it is having trapezoidal back EMF. Hence the design of BLDC motor can be possible for elevator application. Various results can be obtained from the software design of BLDC motor by using FEM or MATLAB SIMULINK software.

\section{REFERENCES}

1. N. Kumaresan, D. Das, Member, IEEE, V. Nayanar, K. Navin Sam and N. Ammasi Gounden 'Development of BLDC Motor based Elevator system suitable for DC Microgrid' 1083-4435 (c) 2015 IEEE.

2. Hosein Bakhtiarzadeh Abdullah Polat Lale T. Ergene 'Design and Analysis of a Permanent MagnetSynchronous Motor for Elevator Applications' 978-1-5090-4489-4/17/\$31.00 @2017 IEEE

3. Vaibhav W. Nage, Sanjay M. Shinde 'An Elevator Driven by Single-Sided LinearInduction Motor (SLIM)' ISBN No.978-14673-9545-8

4. Electric motors for elevators by Devid Herries focus on machine, motors and pumps February 2013 Elevator World

5. A. Nagarajan, T. Dinesh Kumar, 'Design of Switched Reluctance Motor for Elevator Application' Journal of Asian Scientific Research, 3(3):258-267, 2013. 
6. H. S. Mok, G. H. Choe, D. K. Kim Y. S. Jeon, and J. S. Ryu, "A New Simulation Model of BLDC Motor With Real Back EMF Waveform," in Proc. 7th Power Electronics Workshop, Blacksburg, VA, 2000, pp. 217 - 220.

7. J. W. Kolar, A. Looser, B. Wrzecionko and M. Casey, "High-Temperature $(250 \circ \mathrm{C} / 500 \circ \mathrm{F}) 19000$ min-1 BLDC Fan for Forced Air-Cooling of Advanced Automotive Power Electronics," IEEE/ASME Trans. Mechatron., vol. 20, no. 1, pp. 37 - 49, Feb. 2015.

8. A. Gundogan, H. Bai, C. Jiang, A. Kotrba, A. Taylor, A. Yetkin and F. Yang, "Design of a High-Efficiency Minimum-TorqueRipple 12-V/1-kW Three-Phase BLDC Motor Drive System for Diesel Engine Emission Reductions," IEEE Trans. Veh. Technol., vol. 63, no. 7, pp. 3107 - 3115, Sept. 2014.

9. J.H. Kim, J.H. Choi, I.S. Jung, and J. S. Park, "Control Scheme for Efficiency Improvement of slim type BLDC Motor," in Proc. Int. PE drives, Autom. Motion, Ischia, 2014, pp. 820 - 824.

10. K. M. Zakariah, R. Shanmugasundram, and N. Yadaiah, "Implementation and Performance Analysis of Digital Controllers for Brushless DC Motor Drives" IEEE/ASME Trans. Mechatron., vol. 19, no. 1, pp. 213 - 224, Feb. 2014.

11. H. A. Toliyat and S. B. Ozturk, "Direct Torque and Indirect Flux Control of BLDC Motor" IEEE/ASME Trans. Mechatron., vol. 16, no. 2, pp. $351-360$, Apr. 2011.

12. M. H. Lee, H.W. Park, S. J. Park, and F. Harashima, "A New Approach for Minimum-Torque-Ripple Maximum-Efficiency Control of BLDC Motor" IEEE Trans. Ind. Elec., vol. 47, no. 1, pp. 109 - 114, Feb. 2000.

13. Katti, D. P., \& Srinivas, A. Asymmetric Parallel Converter Based High-Power Statcom Applied To Bldc Motor Drive.

14. H. Zhang, F. Peng \& X. Nian, "Regenerative Braking System of Electric Vehicle Driven by Brushless DC Motor" IEEE Trans. Ind. Elect., vol. 61, no. 10, pp. 5798 - 5808, Oct. 2014.

15. M. Ektesabi and A. Tashakori, "Fault Diagnosis of In-wheel BLDC Motor Drive for Electric Vehicle Application" in Proc. IEEE Intell. Veh. Symp., Gold Coast, QLD, 2013, pp, 925 - 930.

16. A. Rowe, S. Demidenko, G. S. Guptal and "Instrumentation and Control of a High Power BLDC Motor for Small Vehicle Applications" in Proc. IEEE Int. Inst. Meas. Technol. Conf., Graz, 2012, pp. 559 - 564.

17. P. B. Bobba and K. R. Rajagopal, "Compact Regenerative Braking Scheme for a PM BLDC Motor Driven Electric TwoWheeler" in Proc. Joint Int. Conf. PE., Drives Energy Syst. \& Power India, New Delhi, 2010, pp. 1 - 5.

18. Brushless Permanent Magnet Motor Design/Dr. Duane Hanslman.--2nd ed.p.cm. 
